doi:10.4149/neo_2015_044

\title{
Identification of biomarkers for metastatic osteosarcoma based on DNA microarray data
}

\author{
Q. WANG*
}

Department of Orthopedics, The Second Affiliated Hospital of Harbin Medical University, Harbin, Heilongjiang, 150086, PRC

*Correspondence: QiangWangqwer@163.com

Received June 3, 2014 / Accepted October 20, 2014

Osteosarcoma (OS) is a malignant bone tumor very often with pulmonary metastasis and is the main cause of OS mortality. The objective of this study was to screen for possible biomarkers of metastatic OS to explore the mechanisms of pulmonary metastasis of OS through network construction. GSE14359 was downloaded from the Gene Expression Omnibus database, which included 5 samples from conventional OS group with 2 replicates and 4 samples from OS pulmonary metastasis group in duplicate. Differentially expressed genes (DEGs) between two groups were identified by limma packages in R and classical t-test with the threshold of the false discovery rate $(F D R)<0.05$. The Database for Annotation, Visualization and Integrated Discovery (DAVID) were then used to perform functional annotation (FDR $<0.01)$. Differential coexpression network was constructed with subspace differential coexpression analysis (SDC), and genes with high degrees in the differential coexpression network were identified.

A total of 1344 genes were screened as DEGs, including 677 up- and 667 down-regulated DEGs in the pulmonary metastasis of OS. Thirty-one significantly enriched functions were obtained, such as blood vessel morphogenesis, defense response, cell death and so on. DEGs with high degrees (brain-specific angiogenesis inhibitor 2 (BAI2), formin-like 1 (FMNL1), dualspecificity phosphatase 7 (DUSP7), transient receptor potential melastatin 2 (TRPM2), CBP80/20-dependent translation initiation factor (KIAA0427) and C120rf35) in the differential coexpression network were found.

BAI2, FMNL1, DUSP7 and TRPM2 may be useful markers for predicting tumor metastasis and therapeutic targets for the treatment of OS patients with metastasis.

Key words: osteosarcoma, differentially expressed genes, differential coexpression network, gene ontology

Osteosarcoma (OS) is the most common primary malignant cancer of the bone in both children and young adults [1]. Moreover, approximately $15-20 \%$ of patients present with discernable metastasis [2], frequently for lung [3]. Though the overall recurrent-free survival rate over 5 years remains approximately $65 \%$ with neoadjuvant chemotherapy combined with surgery, while when pulmonary metastasis, less than $30 \%$ [4]. In addition, neoadjuvant chemotherapy remains controversial in the world [5]. The treatment for OS is very challenging. Hence, it is important to identify molecular targets to prevent pulmonary metastases during the early stage, and further to improve the prognosis of OS patients.

The underlying pathogenesis has been difficult to establish because of its heterogeneous histology and complex etiology. Extensive efforts have been made to explore the potential etiology and molecular mechanisms. Reversion-inducing cysteine rich protein with Kazal motifs (RECK), a member of antiangiogenic factors, is down-regulated in OS [6]. The expression level of TGF- $\beta 1$ is significantly higher in high-grade OS than low-grade OS [7]. Densmore et al. have shown that p53 can effectively reduce the number and the size of lung metastases in OS cases, and also relieve the systemic toxicity by aerosol gene therapy with PEI-p53 complexes [8]. Further, A former research has reported that the human homologue of the murine double minute 2 gene (MDM2), as a regulator of p53 protein function, might be related to tumor progression and metastasis in OS [9]. A previous study also reported that high Ezrin expression was linked to pulmonary metastasis in an OS mouse model partially dependent on activation of Mitogen-Activated Protein Kinases (MAPK) [10]. Matrix metalloproteinases (MMPs) including MMP-2 and MMP-9 have been revealed to be essential in the degradation of base- 
ment membrane and extracellular matrix considered to be crucial in the process of invasion and metastasis of OS [11, 12]. Kayaga et al. has demonstrated that the adenoviral IL-12 gene delivery via instillation effectively inhibited the growth of OS metastases in lung [13]. However, the highly complex molecular mechanisms of OS lung metastases are still poorly understood.

Nowadays, microarray analysis has been applied to observe the alterations of gene levels and screen for potential targets in OS [14]. Therefore, more researchers made use of bioinformatics methods to analyze the information of GSE14359 offered by Guenther et al. [15] who analyzed the expression of EphA2 in OS and the activation of the mitogenic signaling pathway. A previous study has demonstrated that some pathways play important roles in the progression of OS such as phosphatidylinositol 3-kinase (PI3K)/AKT pathway, antigen processing and presentation, focal adhesion and adherens junction [16]. However, the differential coexpression network based on the DEGs was not analyzed.

Hence, in this study, we also employed the bioinformatics methods to identify the DEGs in the OS lung metastases tumor samples, and built a differential coexpression network based on the DEGs. Furthermore, relevant genes and functional enrichment analysis of DEGs were analyzed to explore the potential molecular mechanisms of OS lung metastases tumor.

\section{Materials and methods}

Analysis of Affymetrix microarray data. The gene expression profile of GSE14359 [15] was downloaded from the National Center of Biotechnology Information (NCBI) Gene Expression Omnibus (http://www.ncbi.nlm.nih.gov/ geo/) which was based on GPL96 platform of (HG-U133A) Affymetrix Human Genome U133A Array. In this study, gene microarray data of 5 conventional OS samples (including 2 females and 3 males, the age ranging from 7 to 74 years old, the grade from 2 to 3 ) with 2 replicates and 4 OS pulmonary metastasis samples (including 3 females and 1 male, the age ranging from 21 to 45 years old, the grade from 1 to 3 ) in duplicate were obtained. Raw data and the probe annotation files were downloaded for further analysis.

Data processing and identification of DEGs. The Affy package [17] from Bioconductor and Affy probe annotation files provided by Brain Array Lab were used to preprocess the gene expression profile of GSE14359. Specific steps were as follows: data in CEL format were converted into expression measures, followed by background adjustment, quartile data normalization using the robust multiarray average (RMA) algorithm [18], and probe summarization. Finally, the gene expression matrix was obtained.

The linear models for microarray data (Limma) package [19] in R language and the classical t-test were applied in our analysis to identify differential expressed genes (DEGs) between samples. The false discovery rate of P-value $(F D R)<$
0.05 was chosen as the cut-off criterion which was calculated using the Benjamini \& Hochberg [20] method.

Cluster analysis of DEGs. To analyze the changes of DEGs between conventional OS samples and OS pulmonary samples, the gplots package [21] of Bioconductor was used to build the cluster heat map of DEGs. The matrix of mean expression levels of DEGs was formed between conventional OS samples and OS pulmonary samples. $|\log 2 \mathrm{FC}|>2$ were selected as the cut-off criteria.

Gene ontology functional enrichment analysis. Gene ontology (GO) analysis has been used as functional enrichment studies of large-scale genes frequently [22]. GO functional enrichment analysis was performed with Database for Annotation, Visualization and Integrated Discovery (DAVID), which is a tool providing a comprehensive set of functional annotation for researchers to understand the biological meaning behind a large number of genes [23]. The FDR $<0.01$ was considered statistically significant.

Differential coexpression network construction. Interaction networks of differential coexpression genes were constructed with subspace differential coexpression analysis (SDC) [24]. Specific steps are as follows: (1) subspace DC patterns were obtained using SDC, controlling $\mathrm{r}=0.2, \mathrm{~d}=0.2$ and minimum size $=3$; (2) the subspace DC patterns without DEGs were filtered. The involved genes were used to construct the differential coexpression network. Based on this information, we constructed a differential coexpression network and screened the hub genes with the highest number of interactions using Cytoscape [25] .

\section{Results}

Microarray data analysis. Based on the research criterion (FDR < 0.05), a total of 1344 genes were screened as DEGs, including 677 up- and 667 down-regulated DEGs after microarray analysis.

The cluster analysis of the DEGs. Based on the $|\log 2 \mathrm{FC}|>$ 2, 258 DEGs (including 227 up- and 31 down-regulated DEGs) were obtained between conventional OS samples and OS pulmonary samples. Then, the cluster analysis was performed to explore the changes of the 258 DEGs. The cluster heat map was shown in Figure 1.

GO enrichment analysis. We used the DAVID to identify GO enriched functions. The FDR less than 0.01 was chosen as threshold, 31 significantly enriched functions were obtained (Table 1). The most remarkable function was regulation of cell proliferation $(\mathrm{FDR}=4.11 \mathrm{E}-05)$. The other significant functions included blood vessel morphogenesis (FDR $=0.0027)$, defense response $(F D R=0.0028)$, cell death $(F D R=0.0035)$ and so on.

Differential coexpression network. Networks of differential coexpression genes were constructed with SDC. Firstly, subspace DC patterns were obtained using SDC, controlling $\mathrm{r}=0.2, \mathrm{~d}=0.2$ and minimum size $=3$. Under this condition, we obtained 284 subspace DC patterns in pulmonary metastasis 
OS and the conventional OS, including 2 with the size of 5 , 25 with the size of 4 , and 257 with the size of 3 . Submodules were converted to the corresponding network, there were 437 interaction pairs which contains 67 genes. Then, based on DEGs, subspace DC patterns without DEGS were filtered. A total of 74 submodules were got, including 69 with the size of 3,5 with the size of 4 . In our study, 42 genes and 135 edges were involved in the networks (Figure 2), moreover, 12 nodes were highest degrees in the differential coexpression network (Table 2). The differential coexpression network contained a total of 7 DEGs among which 6 DEGs with the higher degrees including formin-like 1 (FMNL1) (degree $=17)$, brain-specific angiogenesis inhibitor 2 (BAI2) (degree $=11)$, dual-specificity phosphatase 7 (DUSP7) $($ degree $=12)$, transient receptor potential melastatin $2($ TRPM2) (degree $=9)$, CBP80/20dependent translation initiation factor (KIAA0427) $($ degree $=$ $10)$ and C120rf35 (degree $=14)$.

\section{Discussion}

In the current study, we investigated gene expression profile GSE14359 and explored the underlying molecular mechanisms of metastatic OS using bioinformatics methods. Totally 1344 DEGs including 677 up- and 667 down-regulated DEGs were screened. Thirty-one significantly enriched functions were obtained, such as regulation of cell proliferation, defense response, cell death, blood vessel morphogenesis and so on. Six DEGs including FMNL1, BAI2, DUSP7, TRPM2, KIAA0427 and C120rf35 had higher degrees in the differential coexpression network.

The development of metastasis is a major cause of death in many human cancers. Growing evidence indicates that the actin-based processes, such as the cell polarity, cell migration,

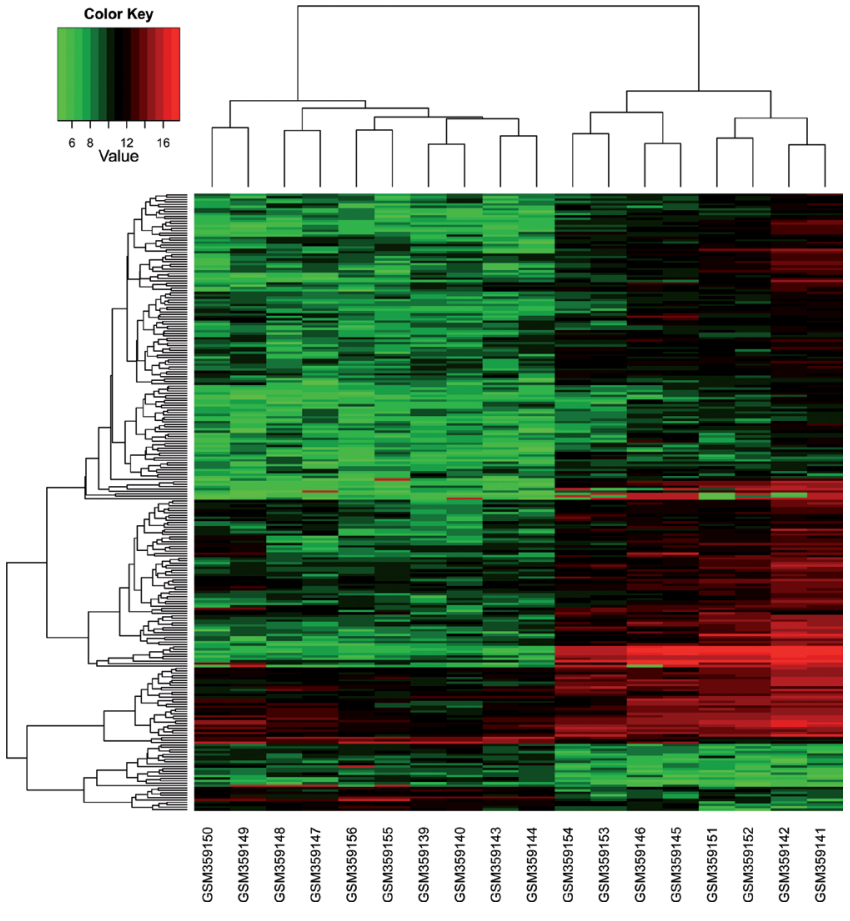

Figure 1. The cluster heat map of the $\mathbf{2 5 8}$ differentially expressed genes (DEGs). The color scale represents the relative levels of gene expression; horizontal axis represents samples; vertical coordinate represents DEGs.

and filopodium formation, may also be important in advanced tumors and may correlate well with their invasion into adjacent tissues and the formation of metastases [26, 27]. FMNL1 is a member of the diaphanous-related formins (DRFs) that regulate the functions of the actin cytoskeleton and Rho fam-

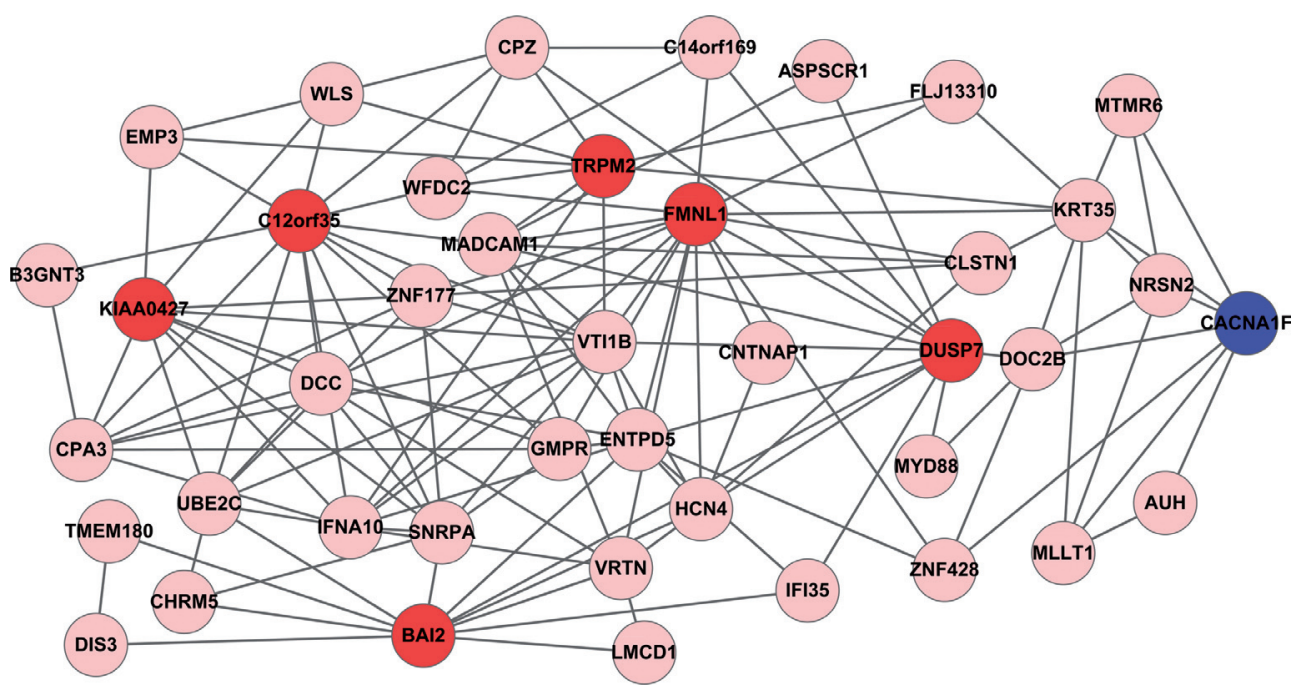

Figure 2. The constructed differential coexpression network involving 42 genes and 135 edges. The nodes represent the genes; the edges represent the coexpression relationship of DEGs; the red color nodes represent up-regulated DEGs; blue color nodes represent down-regulated DEGs and pink color nodes represent non-differential expression genes. 
Table 1. Functional enrichment analysis of differentially expressed genes.

\begin{tabular}{|c|c|c|c|c|c|}
\hline Term ID & Term name & Total_gene & Significant_gene & $\mathbf{P}$ & FDR \\
\hline GO:0042127 & regulation of cell proliferation & 787 & 111 & $1.06 \mathrm{E}-08$ & $4.11 \mathrm{E}-05$ \\
\hline GO:0010033 & response to organic substance & 721 & 97 & $9.57 \mathrm{E}-07$ & 0.0019 \\
\hline GO:0008219 & cell death & 719 & 95 & $2.70 \mathrm{E}-06$ & 0.0035 \\
\hline GO:0048514 & blood vessel morphogenesis & 211 & 39 & $2.77 \mathrm{E}-06$ & 0.0027 \\
\hline GO:0009611 & response to wounding & 530 & 75 & $3.11 \mathrm{E}-06$ & 0.0024 \\
\hline GO:0016265 & death & 724 & 95 & $3.69 \mathrm{E}-06$ & 0.0024 \\
\hline GO:0010941 & regulation of cell death & 815 & 104 & $4.21 \mathrm{E}-06$ & 0.0023 \\
\hline GO:0006952 & defense response & 615 & 83 & $5.68 \mathrm{E}-06$ & 0.0028 \\
\hline GO:0043067 & regulation of programmed cell death & 812 & 103 & $6.12 \mathrm{E}-06$ & 0.0026 \\
\hline GO:0042981 & regulation of apoptosis & 804 & 102 & 7.01E-06 & 0.0027 \\
\hline GO:0008284 & positive regulation of cell proliferation & 414 & 61 & 8.47E-06 & 0.0030 \\
\hline GO:0008285 & negative regulation of cell proliferation & 361 & 55 & $9.62 \mathrm{E}-06$ & 0.0031 \\
\hline GO:0048878 & chemical homeostasis & 512 & 71 & $1.19 \mathrm{E}-05$ & 0.0036 \\
\hline GO:0010647 & positive regulation of cell communication & 329 & 51 & $1.31 \mathrm{E}-05$ & 0.0036 \\
\hline GO:0007267 & cell-cell signaling & 600 & 80 & $1.35 \mathrm{E}-05$ & 0.0035 \\
\hline GO:0009967 & positive regulation of signal transduction & 295 & 47 & $1.50 \mathrm{E}-05$ & 0.0036 \\
\hline GO:0001568 & blood vessel development & 245 & 41 & $1.79 \mathrm{E}-05$ & 0.0041 \\
\hline GO:0010942 & positive regulation of cell death & 435 & 62 & $2.01 \mathrm{E}-05$ & 0.0043 \\
\hline GO:0001525 & angiogenesis & 148 & 29 & $2.17 \mathrm{E}-05$ & 0.0044 \\
\hline GO:0001944 & vasculature development & 251 & 41 & 3.17E-05 & 0.0061 \\
\hline GO:0032101 & regulation of response to external stimulus & 159 & 30 & $3.19 \mathrm{E}-05$ & 0.0059 \\
\hline GO:0043068 & positive regulation of programmed cell death & 433 & 61 & $3.35 \mathrm{E}-05$ & 0.0059 \\
\hline GO:0030005 & cellular di-, tri-valent inorganic cation homeostasis & 227 & 38 & $3.78 \mathrm{E}-05$ & 0.0064 \\
\hline GO:0031644 & regulation of neurological system process & 153 & 29 & 4.07E-05 & 0.0066 \\
\hline GO:0006954 & inflammatory response & 325 & 49 & 4.10E-05 & 0.0064 \\
\hline GO:0043065 & positive regulation of apoptosis & 430 & 60 & 5.19E-05 & 0.0077 \\
\hline GO:0055066 & di-, tri-valent inorganic cation homeostasis & 239 & 39 & $5.21 \mathrm{E}-05$ & 0.0075 \\
\hline GO:0055074 & calcium ion homeostasis & 188 & 33 & $5.28 \mathrm{E}-05$ & 0.0073 \\
\hline GO:0001501 & skeletal system development & 319 & 48 & $5.29 \mathrm{E}-05$ & 0.0071 \\
\hline GO:0006874 & cellular calcium ion homeostasis & 183 & 32 & $7.54 \mathrm{E}-05$ & 0.0097 \\
\hline GO:0012501 & programmed cell death & 611 & 78 & $7.85 \mathrm{E}-05$ & 0.0098 \\
\hline
\end{tabular}

ily guanosine triphosphatases (GTPases) [28, 29]. Rho family has close relationship with tumor development. FMNL1 may regulate Rho-related signal pathways involved in polarity

Table 2. The top 12 genes with the highest degree in the differential coexpression network.

\begin{tabular}{llcc}
\hline Gene ID & Gene symbol & Degree & DEG \\
\hline 576 & BAI2 & 11 & Yes \\
752 & FMNL1 & 17 & Yes \\
10490 & VTI1B & 13 & No \\
1849 & DUSP7 & 12 & Yes \\
7229 & TRPM2 & 9 & Yes \\
9811 & KIAA0427 & 10 & Yes \\
55196 & C120rf35 & 14 & Yes \\
957 & ENTPD5 & 11 & No \\
3446 & IFNA10 & 10 & No \\
3886 & KRT35 & 9 & No \\
6626 & SNRPA & 9 & No \\
8174 & MADCAM1 & 9 & No \\
\hline
\end{tabular}

control, infiltration, migration and metastasis [30]. Alteration of FMNL1 expression was described in several tumor tissues and reported to be associated with tumor progression. For example, FMNL1 expresses highly in many epithelial cancer cell lines [31]. Moreover, FMNL1 regulates cell motility in macrophages and also promotes proliferation and migration in leukemia cells [32, 33]. However, the current knowledge about the involvement of FMNL1 in OS pulmonary metastasis is little. In our study, FMNL1 was significantly up-regulated in the OS lung metastases tumor samples compared with the conventional OS samples. In light of these results, we infer that FMNL1 might be a potential metastasis associated gene of OS.

In our study, we found DEGs were mostly enriched in blood vessel development, angiogenesis, and vasculature development. It is well known that angiogenesis and vasculature development play an important role in the process of tumor growth and metastasis [34] and can be stimulated by positive factors, such as vascular endothelial growth factor (VEGF) [35]. BAI2, one of DEGs, was shown to be significantly up- 
regulated in OS lung metastases tumor samples in the present study. Previous studies have indicated that high recurrence rate and high metastatic potential of OS are associated with high levels of vascularisation [36, 37]. The increased mRNA expression of VEGF has been reported in OS [38]. Previously, Jeong et al. pointed out that decreased BAI2 induced increased VEGF transcription through decreased GA-binding protein (GABP) under normal conditions and cerebral ischemia [39]. Therefore, we inferred that there is the potential link underlying the negative correlation between BAI2 and VEGF in the metastasis of OS, suggesting that BAI2 can be used as a new target gene to play a role through anti-angiogenesis in OS metastasis.

DUSP7 was also demonstrated to be up-regulated in our study. DUSP7 belongs to a class of DUSPs which are negative regulators of MAPKs that function by dephosphorylating [40]. MAPK plays a major role in mediating inflammatory, oncogenic signals as well as aggressive behaviour of OS through expression of Raf- 1 , pMEK1/2 and pERK1/2 which were associated with the occurrence of distant metastasis and poor overall survival $[41,42]$. In addition, it is known that the MAPK pathway is involved in the induction of MMP-2, which has been implicated in the invasion and metastasis of OS [43]. Hence, DUSP7 might be an important gene contributing for development metastasis of OS.

Apoptosis, also known as programmed cell death, plays an important role in the development of OS. There is evidence that it may be effective to induce the apoptotic processes to prevent tumor formation, recurrence and metastasis [44-46]. B-cell lymphoma 2 (Bcl-2) is a member of Bcl-2 protein family which is comprised of anti-apoptotic proteins and pro-apoptotic proteins. In clinical trials, the expression level of Bcl-2 has been shown higher in OS patients with recurrent pulmonary metastases compared with those with primary tumors, and the expression of Bcl-2 was also shown to be closely associated with the prognosis of OS patients [47, 48]. TRPM2, one member of the TRPM subfamily, is a $\mathrm{Ca}^{2+}$-permeable, non-selective cation channel involving in apoptosis. TRPM2 was shown to modulate hematopoitic cell death though activation of caspases and poly ADP-ribose polymerase (PARP) cleavage [49]. Knocking down TRPM2 with siRNA technique inhibited the growth of prostate cancer cells rather than of non-cancerous cells [50]. TRPM2 mRNA was found in many primary breast tumors, but no apparent relationship to survival [51]. Besides, overexpression of TRPM2 increased susceptibility of melanoma to apoptosis [52]. Based on these conclusions, we speculate TRPM2 may play a critical role in the metastasis of OS.

In conclusion, the identified DEGs, especially BAI2, FMNL1, DUSP7 and TRPM2, may be pivotal genes for the metastasis development in OS, and these genes may be useful markers for predicting tumor metastasis and therapeutic targets for the treatment of OS patients with metastasis. However, there are two shortcomings in this paper. Firstly, the sample size was too small. Secondly, study was carried out based on the bioinformatics methods and the conclusions have not been proved by relevant experiments yet. Necessarily, further experiments are indispensable to verify the effects and mechanisms of BAI2, FMNL1, DUSP7 and TRPM2 in metastatic OS.

\section{References}

[1] OTTAVIANI G, JAFFE N. The epidemiology of osteosarcoma. Cancer Treat Res. 2009; 152: 3-13. http://dx.doi. org/10.1007/978-1-4419-0284-9 1

[2] KASTE SC PC, CAIN AM ET AL. Metastases detected at the time of diagnosis of primary pediatric extremity osteosarcomaat diagnosis: imaging features. Cancer. 1999; 86: 1602-1608. http://dx.doi.org/10.1002/(SICI)1097-0142(19991015)86:8<1602::AID-CNCR31>3.0.CO;2-R

[3] SALINAS-SOUZA C, DE OLIVEIRA R, ALVES MT, GARCIA FILHO RJ, PETRILLI AS et al. The metastatic behavior of osteosarcoma by gene expression and cytogenetic analyses. Hum Pathol. 2013; 44: 2188-2198. http://dx.doi. org/10.1016/j.humpath.2013.04.013

[4] MARINA N, GEBHARDT M, TEOT L, GORLICK R. Biology and therapeutic advances for pediatric osteosarcoma. oncologist. 2004; 9: 422-441. http://dx.doi.org/10.1634/ theoncologist.9-4-422

[5] BACCI G, PICCI P, RUGGIERI P, MERCURI M, AVELLA M et al. Primary chemotherapy and delayed surgery (neoadjuvant chemotherapy) for osteosarcoma of the extremities. The Istituto Rizzoli Experience in 127 patients treated preoperatively with intravenous methotrexate (high versus moderate doses) and intraarterial cisplatin. Cancer. 1990; 65: 2539-2553. http:// dx.doi.org/10.1002/1097-0142(19900601)65:11<2539::AIDCNCR2820651125>3.0.CO;2-M

[6] CLARK JC, THOMAS DM, CHOONG PF, DASS CR. RECK-a newly discovered inhibitor of metastasis with prognostic significance in multiple forms of cancer. Cancer Metastasis Rev. 2007; 26: 675-683. http://dx.doi.org/10.1007/s10555007-9093-8

[7] FUCHS B, PRITCHARD DJ. Etiology of osteosarcoma. Clin Orthop Relat Res. 2002: 40-52. http://dx.doi. org/10.1097/00003086-200204000-00007

[8] DENSMORE CL, KLEINERMAN ES, GAUTAM A, JIA SF, XU B et al. Growth suppression of established human osteosarcoma lung metastases in mice by aerosol gene therapy with PEI-p53 complexes. Cancer Gene Ther. 2001; 8: 619-627. http://dx.doi.org/10.1038/sj.cgt.7700343

[9] LADANYI M, CHA C, LEWIS R, JHANWAR SC, HUVOS AG et al. MDM2 gene amplification in metastatic osteosarcoma. Cancer Res. 1993; 53: 16-18.

[10] KHANNA C, WAN X, BOSE S, CASSADAY R, OLOMU O et al. The membrane-cytoskeleton linker ezrin is necessary for osteosarcoma metastasis. Nat Med. 2004; 10: 182-186. http:// dx.doi.org $/ 10.1038 / \mathrm{nm} 982$

[11] STAMENKOVIC I. Matrix metalloproteinases in tumor invasion and metastasis. Semin Cancer Biol. 2000; 10: 415-433. http://dx.doi.org/10.1006/scbi.2000.0379

[12] TANIMURA S, KADOMOTO R, TANAKA T, ZHANG YJ, KOUNO I et al. Suppression of tumor cell invasiveness by 
hydrolyzable tannins (plant polyphenols) via the inhibition of matrix metalloproteinase-2/-9 activity. Biochem Biophys Res Commun. 2005; 330: 1306-1313. http://dx.doi.org/10.1016/j. bbrc.2005.03.116

[13] KAYAGA J, SOUBERBIELLE BE, SHEIKH N, MORROW WJ, SCOTT-TAYLOR T et al. Anti-tumour activity against B16F10 melanoma with a GM-CSF secreting allogeneic tumour cell vaccine. Gene Ther. 1999; 6: 1475-1481. http://dx.doi. org/10.1038/sj.gt.3300961

[14] WOLF M, EL-RIFAI W, TARKKANEN M, KONONEN J, SERRA $M$ et al. Novel findings in gene expression detected in human osteosarcoma by cDNA microarray. Cancer Genet Cytogenet. 2000; 123: 128-132. http://dx.doi.org/10.1016/ S0165-4608(00)00319-8

[15] FRITSCHE-GUENTHER R, NOSKE A, UNGETH M U, KUBAN RJ, SCHLAG PM et al. De novo expression of EphA2 in osteosarcoma modulates activation of the mitogenic signalling pathway. Histopathology. 2010; 57: 836-850. http://dx.doi. org/10.1111/j.1365-2559.2010.03713.x

[16] LUO Y, DENG Z, CHEN J. Pivotal regulatory network and genes in osteosarcoma. Archives of medical science : AMS. 2013; 9: 569-575. http://dx.doi.org/10.5114/aoms.2012.30956

[17] GAUTIER L, COPE L, BOLSTAD BM, IRIZARRY RA. affy-analysis of Affymetrix GeneChip data at the probe level. Bioinformatics. 2004; 20: 307-315. http://dx.doi.org/10.1093/ bioinformatics/btg 405

[18] IRIZARRY RA, HOBBS B, COLLIN F, BEAZER-BARCLAY YD, ANTONELLIS KJ et al. Exploration, normalization, and summaries of high density oligonucleotide array probe level data. Biostatistics. 2003; 4: 249-264. http://dx.doi. org/10.1093/biostatistics/4.2.249

[19] SMYTH GK. Limma: linear models for microarray data. Bioinformatics and computational biology solutions using $\mathrm{R}$ and Bioconductor. Springer; 2005. p. 397-420.

[20] BENJAMINI Y, DRAI D, ELMER G, KAFKAFI N, GOLANI I. Controlling the false discovery rate in behavior genetics research. Behav Brain Res. 2001; 125: 279-284. http://dx.doi. org/10.1016/S0166-4328(01)00297-2

[21] WARNES GR, BOLKER B, BONEBAKKER L, GENTLEMAN R, HUBER W et al. gplots: Various R programming tools for plotting data. R package version. 2009; 2(4).

[22] ASHBURNER M, BALL CA, BLAKE JA, BOTSTEIN D, BUTLER $\mathrm{H}$ et al. Gene ontology: tool for the unification of biology. The Gene Ontology Consortium. Nat Genet. 2000; 25: 25-29. http://dx.doi.org/10.1038/75556

[23] HUANG DA W, SHERMAN BT, LEMPICKI RA. Systematic and integrative analysis of large gene lists using DAVID bioinformatics resources. Nat Protoc. 2009; 4: 44-57. http://dx.doi. org/10.1038/nprot.2008.211

[24] FANG G, KUANG R, PANDEY G, STEINBACH M, MYERS CL et al. Subspace differential coexpression analysis: problem definition and a general approach. Pac Symp Biocomput. 2010: 145-156.

[25] SMOOT ME, ONO K, RUSCHEINSKI J, WANG PL, IDEKER T. Cytoscape 2.8: new features for data integration and network visualization. Bioinformatics. 2011;27: 431-432. http:// dx.doi.org/10.1093/bioinformatics/btq675
[26] VASILIEV JM. Cytoskeletal mechanisms responsible for invasive migration of neoplastic cells. The International journal of developmental biology. 2004; 48: 425-439. http://dx.doi. org/10.1387/ijdb.041806jv

[27] WODARZ A, NATHKE I. Cell polarity in development and cancer. Nat Cell Biol. 2007; 9: 1016-1024. http://dx.doi. org/10.1038/ncb433

[28] HIGGS HN. Formin proteins: a domain-based approach. Trends Biochem Sci. 2005; 30: 342-353. http://dx.doi. org/10.1016/j.tibs.2005.04.014

[29] YOUNG KG, COPELAND JW. Formins in cell signaling. Biochim Biophys Acta. 2010; 1803: 183-190. http://dx.doi. org/10.1016/j.bbamcr.2008.09.017

[30] KOVAR DR. Cell polarity: formin on the move. Curr Biol. 2006; 16: R535-538. http://dx.doi.org/10.1016/j.cub.2006.06.039

[31] COLON-FRANCO JM, GOMEZ TS, BILLADEAU DD. Dynamic remodeling of the actin cytoskeleton by FMNL1gamma is required for structural maintenance of the Golgi complex. J Cell Sci. 2011; 124: 3118-3126. http://dx.doi.org/10.1242/ jcs. 083725

[32] FAVARO P, TRAINA F, MACHADO-NETO JA, LAZARINI M, LOPES MR et al. FMNL1 promotes proliferation and migration of leukemia cells. J Leukoc Biol. 2013; 94: 503-512. http://dx.doi.org/10.1189/jlb.0113057

[33] YAYOSHI-YAMAMOTO S, TANIUCHI I, WATANABE T. FRL, a novel formin-related protein, binds to Rac and regulates cell motility and survival of macrophages. Mol Cell Biol. 2000; 20: 6872-6881. http://dx.doi.org/10.1128/MCB.20.18.6872$\underline{6881.2000}$

[34] FOLKMAN J. Angiogenesis in cancer, vascular, rheumatoid and other disease. Nat Med. 1995; 1: 27-31. http://dx.doi. org/10.1038/nm0195-27

[35] LEUNG DW, CACHIANES G, KUANG WJ, GOEDDEL DV, FERRARA N. Vascular endothelial growth factor is a secreted angiogenic mitogen. Science. 1989; 246: 1306-1309. http:// dx.doi.org/10.1126/science.2479986

[36] COOMBER BL, DENTON J, SYLVESTRE A, KRUTH S. Blood vessel density in canine osteosarcoma. Canadian journal of veterinary research $=$ Revue canadienne de recherche veterinaire. 1998; 62: 199-204.

[37] KREUTER M, BIEKER R, BIELACK SS, AURAS T, BUERGER $\mathrm{H}$ et al. Prognostic relevance of increased angiogenesis in osteosarcoma. Clin Cancer Res. 2004; 10: 8531-8537. http:// dx.doi.org/10.1158/1078-0432.CCR-04-0969

[38] CHARITY RM FA, DESHMUKH NS, GRIMER RJ. Vascular endothelial growth factor expression in osteosarcoma. Clin Orthop Relat Res. 2006; 448: 193-198. http://dx.doi. org/10.1097/01.blo.0000205877.05093.c9

[39] JEONG BC, KIM MY, LEE JH, KEE HJ, KHO DH et al. Brain-specific angiogenesis inhibitor 2 regulates VEGF through GABP that acts as a transcriptional repressor. FEBS letters. 2006; 580: 669-676. http://dx.doi.org/10.1016/j. febslet.2005.12.086

[40] OWENS DM, KEYSE SM. Differential regulation of MAP kinase signalling by dual-specificity protein phosphatases. Oncogene. 2007; 26: 3203-3213. http://dx.doi.org/10.1038/ sj.onc. 1210412 
[41] LI GD CZ, ZHANG YQ, GONG HY, TANG H, ZHANG QL. Gene profiling of MAPK pathway in human osteosarcoma. Chinese Joural of Oncology. 2009; 31: 340-345.

[42] NA KY KY, PARK YK. Mitogen-activated protein kinase pathway in osteosarcoma. Pathology. 2012; 44: 540-546. http://dx.doi.org/10.1097/PAT.0b013e32835803bc

[43] SPALLAROSSA P, ALTIERI P, GARIBALDI S, GHIGLIOTTI G, BARISIONE C et al. Matrix metalloproteinase-2 and -9 are induced differently by doxorubicin in $\mathrm{H} 9 \mathrm{c} 2$ cells: The role of MAP kinases and $\mathrm{NAD}(\mathrm{P}) \mathrm{H}$ oxidase. Cardiovasc Res. 2006; 69: 736-745. http://dx.doi.org/10.1016/j. cardiores.2005.08.009

[44] LORENZ HM, HERRMANN M, WINKLER T, GAIPL U, KALDEN JR. Role of apoptosis in autoimmunity. Apoptosis. 2000; 5: 443-449. http://dx.doi.org/10.1023/A:1009692902805

[45] SCHULZE-BERGKAMEN H, KRAMMER PH. Apoptosis in cancer-implications for therapy. Semin Oncol. 2004; 31: 90-119. http://dx.doi.org/10.1053/j.seminoncol.2003.11.006

[46] WYLLIE AH. Apoptosis and the regulation of cell numbers in normal and neoplastic tissues: an overview. Cancer Metastasis Rev. 1992; 11: 95-103. http://dx.doi.org/10.1007/ $\underline{B F 00048057}$

[47] FERRARI S, BERTONI F, ZANELLA L, SETOLA E, BACCHINI $P$ et al. Evaluation of P-glycoprotein, HER-2/ErbB-2, p53, and Bcl-2 in primary tumor and metachronous lung metastases in patients with high-grade osteosarcoma. Cancer. 2004; 100: 1936-1942. http://dx.doi.org/10.1002/cncr.20151
[48] WU X, CAI ZD, LOU LM, ZHU YB. Expressions of p53, c-MYC, BCL-2 and apoptotic index in human osteosarcoma and their correlations with prognosis of patients. Cancer Epidemiol. 2012; 36: 212-216. http://dx.doi.org/10.1016/j. canep.2011.08.002

[49] ZHANG W, HIRSCHLER-LASZKIEWICZ I, TONG Q, CONRAD K, SUN SC et al. TRPM2 is an ion channel that modulates hematopoietic cell death through activation of caspases and PARP cleavage. Am J Physiol Cell Physiol. 2006; 290: C1146-1159. http://dx.doi.org/10.1152/ ajpcell.00205.2005

[50] ZENG X, SIKKA SC, HUANG L, SUN C, XU C et al. Novel role for the transient receptor potential channel TRPM2 in prostate cancer cell proliferation. Prostate Cancer Prostatic Dis. 2010; 13: 195-201. http://dx.doi.org/10.1038/ pcan.2009.55

[51] RENNIE PS, MAWJI NR, COLDMAN AJ, GODOLPHIN W, JONES EC et al. Relationship between variant forms of estrogen receptor RNA and an apoptosis-related RNA, TRPM-2, with survival in patients with breast cancer. Cancer. 1993; 72: 3648-3654. http://dx.doi.org/10.1002/1097-0142(19931215)72:12<3648::AID-CNCR2820721216>3.0.CO;2-L

[52] ORFANELLI U, WENKE AK, DOGLIONI C, RUSSO V, BOSSERHOFF AK et al. Identification of novel sense and antisense transcription at the TRPM2 locus in cancer. Cell Res. 2008; 18: 1128-1140. http://dx.doi.org/10.1038/ cr.2008.296 